\title{
Evaluation of Antibiotic Sensitivity Against Bacterial Diseases Prevalent in Commercial Poultry Farm in Western Part of Bangladesh
}

\author{
Aurangazeb Kabir, Most. Sabina Yasmin, Md. Golam Sarwar, \\ Md. Obaidullah Al Masum, Soshe Ahmed, and Mohammad Mahbubur Rahman
}

\section{ABSTRACT}

A surge in the emergence and spread of antimicrobial resistance (AMR) has become a major concern. The indiscriminate use of antibiotics in poultry farming, increased consumption of poultry products containing antimicrobial residues is likely to hasten the development of multidrug resistance in pathogens, as well as in commensal organisms. To substantiate our knowledge on the status of AMR to the Neomycin, Gentamicin, Levofloxacin, Ciprofloxacin, Doxycycline, Sulfonamide, Amoxicillin and Cephalexin, commonly being used in poultry farms in Rajshahi city (Western Part) of Bangladesh a cross sectional study was carried out using conventional KirbyBauer disc diffusion technique. We tried to identify sensitivity of the stated antibiotics against bacterial samples obtained from 30 liver samples of live birds out of which 24 were layer and 6 were broiler from 10 commercial poultry farms. In our study, we observed that Cephalexin, Neomycin, Gentamicin and Levofloxacin retain superior antimicrobial potency at the rate of $33.33 \%, 23.33 \%, 20 \%$, and $23.33 \%$ respectively. Moreover, Levofloxacin started to show quite $(\mathbf{7 0 \%})$ to moderate $(6.67 \%)$ sensitivity and Neomycin (76.67\%), Gentamicin $(80 \%)$ Cephalexin $(33.33 \%)$ show only quite sensitivity indicating exacerbation of existing antimicrobial resistance through gradually losing their affectivity against microbial infections. On the other hand, during our observation Ciprofloxacin (33.33\%), Amoxicillin (20\%), Doxycycline $(6.67 \%)$ and Sulfonamides $(3.33 \%)$ were found having no sensitivity at all, however, these drugs still being considered as drug of choice for commercial flocks to treat microbial infection. Farmers 'knowledge, attitudes, and practices regarding the use of antibiotics have to be fully compliant in line with manufacturers' recommendations to reduce risk to public health. This study was, therefore, conducted to collect baseline data on the regularly used antibiotics in poultry production and to provide a greater understanding of the potential impact of antimicrobial resistance on public health.

Keywords: Commercial Poultry, Antibiotics, Antibiotic Sensitivity, Antibiotic Resistance.
Submitted : March 11, 2021

Published : April 01, 2021

ISSN: $2684-1827$

DOI: 10.24018 /ejfood.2021.3.2.262

Aurangazeb Kabir

Associate Professor, Dept. of Veterinary and Animal Sciences, University of Rajshahi, Bangladesh.

(e-mail: aurangak@yahoo.com)

Most. Sabina Yasmin

Dept. of Veterinary and Animal Sciences, University of Rajshahi,

Bangladesh.

(e-mail:

sabinayasmin12208306@gmail.com) Md. Golam Sarwar

Dept. of Veterinary and Animal Sciences, University of Rajshahi, Bangladesh.

(e-mail:

golam.sarwar12038314@gmail.com)

Md. Obaidullah Al Masum

Dept. of Veterinary and Animal

Sciences, University of Rajshahi, Bangladesh.

(e-mail: oalmasum93@ gmail.com)

Soshe Ahmed

Associate Professor, Dept. of Veterinary and Animal Sciences,

University of Rajshahi, Bangladesh.

(e-mail: soshe.ahmed @ gmail.com)

Mohammad Mahbubur Rahman*

Professor, Dept. of Veterinary and

Animal Sciences, University of

Rajshahi, Bangladesh.

(e-mail: mmrahman@ ru.ac.bd)

*Corresponding Author

\section{INTRODUCTION}

Bangladesh is one of the densely populated countries of the world and about 80 percent people live in villages and depend on agriculture. The poultry industry in Bangladesh has become an incomparable floor for a quick profit, the generation of local employment, and the creation of cheaper animal proteins. Nowadays it is an integral part of our national economy. The poultry sector is rapidly expanding and has overall $14 \%$ market share in terms of animal output. It is estimated that $37 \%$ of Bangladesh's total meat production is poultry meat alone. The total supply of animal proteins by poultry is approximately between 22 and 27\% [1]. Although poultry sector is developing in our country and in the world day by day but there is also some threats and challenges in this field. There are many diseases which may cause greater economic losses to the poultry keepers \& ultimately to our national economy through some disease conditions. Among these, infectious diseases are the most devastating and frequently reported diseases of poultry industry. Antibiotics are mostly used to treat disease outbreak in poultry species but in most cases, antibiotics are not used properly by the owner and in some cases, they used antibiotics haphazardly and ultimately antibiotic resistance is developed and eventually birds become unprotected and vulnerable to various deadly diseases. That severely compromises the farm productivity and ultimately the economy at national level. 
Antibiotics that are mostly used for the treatment of poultry diseases are as follows-Cephalosporins that includes (Cephalexin, Cefiximeetc.); Tetracyclines include usually (Oxytetracycline, Chlortetracycline, Doxycyclineetc.); Aminoglycosides like (Gentamycin, Kanamycin, Neomycin, Streptomycin etc.), Macrolids as Azithromycin, Quinolones literary named as (Ciprofloxacin, Norfloxacin, Levofloxacin, Enrofloxacin etc.); Penicillin group including (Amoxicillin, Ampicillin, Penicillin etc.) and Sulfonamides drugs. The greater amount of antibiotics used in the feed of poultry is Enrofloxacin $(46.67 \%)$ which is succeeded by ciprofloxacin $(30.00 \%)$ and amoxicillin $(23.33 \%)$ where amoxicillin plus ciprofloxacin and ciprofloxacin plus amoxicillin is also found in case of liver of broilers [2].

Antibiotics are not only used to treat diseases but also used in feeds in larger amount so that production level can be raised by increasing conversion of feed, promoting growth rate, and preventing diseases. The health status of birds can be protected by using antibiotics because it modifies the immunity of birds [3]. Nowadays, antimicrobial resistance (AMR) appears as a serious global threat of rising concern to human, animal, as well as environment health. This is due to the emergence, spread, and persistence of multidrug-resistant (MDR) bacteria or "superbugs" [4]. The plausible causes of AMR include excessive use of antibiotics in animals (food, pets, aquatic) and humans, antibiotics sold over-the-counter, increased international travel, poor sanitation/hygiene, and release of non-metabolized antibiotics or their residues into the environment through manure/feces. At present, the multifaceted etiology of antibiotic resistance has many factors which are at play. These include inadequate regulations and usage imprecision's, awareness deficiency in best practices which steers undue or inept use of antibiotics, use of antibiotics as a poultry and livestock growth promoter rather than to control infection, and online marketing which made the unrestricted availability of low-grade antibiotics very accessible [5], [6]. Many of the studies have showed that treatment indications, choice of the microbial agents, and duration of antibiotic therapy are not appropriate in 30\%$50 \%$ of the cases [7], [9]. A cross sectional study was carried out on indiscriminate use of antibiotics in poultry feed and residues in broilers of Mymensingh city in Bangladesh. On that study they found that about $100 \%$ of liver samples and $20 \%$ of muscle samples contain antibiotic residues and the residue of Enrofloxacin is higher as about $47 \%$, Ciprofloxacin $30.00 \%$ and Amoxicillin is about $23.33 \%$. This may pose potential hazard to public health [2].

Although, there are several studies has been conducted about microbial resistance, but it is not enough. So, more and more study should know about the optimum and fruitful use of antibiotics through antibiotic sensitivity test. One of the most vital organs of our body as well as poultry species is liver which is responsible for different major functions of the body like digestion, metabolism, and absorption. Most of the chemicals including toxin components in the feed and chemical compounds in medicine are also metabolized and detoxified by the liver. The liver thus performs numerous functions to maintain a proper body system, but poultry in modern production systems are facing a lot of challenges that threaten liver health [10].
The present study has been designed to conduct antibiotic sensitivity test by using sample from liver of the susceptible birds from commercial flocks to know which antibiotics are more effective to these birds against bacterial diseases and which are already become resistant. In our studies we do not work to differentiate specific pathogens rather we want to gather knowledge about the overall specific or indiscriminate use of antibiotics by the commercial farmers and to elucidate the reasons entails about the emergence of antibiotic resistance.

\section{METHODOLOGY}

\section{A. Location of the Study Area}

This study was conducted in some selected area of Rajshahi in Bangladesh. Geographically Rajshahi is situated within Barind Tract, $23 \mathrm{~m}$ (75ft) above sea level, and lies at $24^{\circ} 22^{\prime} 26^{\prime \prime} \mathrm{N} 88^{\circ} 36^{\prime} 04^{\prime \prime} \mathrm{E} / 24.37389^{\circ} \mathrm{N} 88.60111^{\circ} \mathrm{E}$. Rajshahi city is situated on the alluvial plains of the Padma River, running through southern side of the city.

\section{B. Study Area}

A cross sectional study was carried out for a period of 6 months from August 2018 to January 2019 including different commercial poultry farms in Rajshahi district. A total of 10 commercial farms were selected for questionnaire study and sample collection. During interview, workers and owners of the live birds were asked question targeting age, level of education, types of bird reared by them, source of birds, feeding and management practices of the birds, experience of antibiotic use in poultry feeds, consequences of antibiotics abuses, left over antibiotics in poultry meat and antibiotic resistance etc.

\section{Sample Collection}

A total of 30 live birds (03 from each farm) and of which 24 were layer and 6 were broiler collected randomly for this study. Birds (both broilers and layers) were collected from those farms whose owners agreed to participate in this study willingly. After slaughtering, liver was collected aseptically in plastic zipper bag from each chicken and was stored at $20{ }^{\circ} \mathrm{C}$ until proceed to extraction procedure.

A study has been conducted to know the proportion of antibiotic residues in broiler birds and it was found that about $100 \%$ of liver sample contain antibiotic residues [2].

\section{Sample preparation}

Preparation was performed following the standard procedure [11].

\section{Grinding of the sample}

Collected liver sample from each bird were cut into small pieces, then weighted about 10-15 $\mathrm{g}$ and grinding was done with mortar and pestle. At the time of grinding a few drops of saline solution was added to the sample to blend it homogenously.

\section{Centrifuging of the sample}

The prepared sample about $5 \mathrm{gm}$ was taken in a centrifuge tube (Falcon tube). After that the mixture was centrifuged at $3000 \mathrm{rpm}$ for 4 minutes. Then the tube was placed out of the centrifuge machine and kept for about 10 minutes at room temperature. 


\section{Placing supernatant at the agar media}

The supernatant was collected by using sterilized cotton buds and it was soaked over the surface of the plate containing Mueller Hinton agar homogenously.

\section{E. Media Preparation}

Mueller Hinton agar (MHA) is most commonly used for antimicrobial susceptibility testing. It was developed by Mueller and Hinton in 1941. Nowadays, it is mostly used for the routine susceptibility testing of microorganism by the Kirby-Bauer disc diffusion technique [12].

TABLE I: COMPOSITION OF MHA

\begin{tabular}{cc}
\hline Ingredients & Gram/Liter \\
\hline Beef Extract & $2.00 \mathrm{~g}$ \\
Starch & $1.50 \mathrm{~g}$ \\
Acid hydro lysate of Casein & $17.50 \mathrm{~g}$ \\
Agar & $17.00 \mathrm{~g}$ \\
Distilled Water & $1000 \mathrm{ml}$ \\
\hline
\end{tabular}

1. Preparation of growth plate by using commercially available Mueller-Hinton Agar (MHA):

$38 \mathrm{~g}$ Mueller Hinton Agar is usually used in $1000 \mathrm{ml}$ distilled water, but I used $3.5 \mathrm{~g}$ in $100 \mathrm{ml}$ of distilled water for preparing 5 petridishes.

2. Procedure

Step 1: $100 \mathrm{ml}$ of distilled water was taken in a glass bottle.

Step 2:3.5 g agar was suspended in it and waited for a while to mix it properly.

Step 3: Then the glass bottle and petridishes were placed in Autoclave machine at $121{ }^{\circ} \mathrm{C}$ for 15 minutes for sterilization.

Step 4: After that cooling was done at room temperature.

Step 5: Pouring of cooled Mueller Hinton Agar into sterile petridishes on a level, horizontal surface to give uniform depth.

Step 6: Then the plates were allowed to solidifyat room temperature.

Step 7: Storing of the plates was done using normal freeze at $4{ }^{\circ} \mathrm{C}$.

\section{F. Selection of Antibiotic Discs}

The antibiotics were Neomycin, Gentamicin, Ciprofloxacin, Doxycycline, Amoxicillin, Levofloxacin, Sulfonamides, \& Cephalexin was used during this study.

\section{G. Antibiotic Disc Placement}

i. The "Conventional Kirby-Bauer disc diffusion" method was used for antibiotic sensitivity test.

ii. The commercially available antibiotic discs were kept on the agar surface using a sterile forceps and pressing tightly to adhere with surface.

iii. Almost 8 antibiotic discs were used throughout the study period to test each of the different samples on the basis of records of previous use of antibiotics and the present crisis.

iv. Then the Plates were placed in upward position inside incubator till 16 hours at $37^{\circ} \mathrm{C}$ temperature.

v. After 16 hours sensitivity of the antibiotic disc was recorded on the basis of the following parameters [13].
TABLE II: INDICATION OF SENSITIVITY MEASURING ZONE OF INHIBITION AROUND ANTIBIOTIC DISCS

\begin{tabular}{|c|c|c|}
\hline Zone around the disc & \multicolumn{2}{|c|}{ Indication of sensitivity } \\
\hline $\begin{array}{l}\text { The absence of clear zone around the } \\
\text { disc }\end{array}$ & - & Not sensitive \\
\hline The clear zones with $1-2 \mathrm{~mm}$ & + & Weakly sensitive \\
\hline The clear zones with 2 to $5 \mathrm{~mm}$ & ++ & Moderate sensitive \\
\hline $\begin{array}{l}\text { The clear zones with } 5 \text { to } 10 \mathrm{~mm} \\
\text { diameter }\end{array}$ & +++ & Quite sensitive \\
\hline $\begin{array}{l}\text { The clear zones with } 10 \text { to } 15 \mathrm{~mm} \\
\text { diameter around the disc }\end{array}$ & ++++ & Highly sensitive \\
\hline
\end{tabular}

\section{RESULTS}

\section{A. Antibiotics Highly Sensitive against Bacterial Samples}

Among the highly sensitive antibiotics Cefalexin, also spelled Cephalexin has been proven to be more effective than its other counterparts like Neomycin, Gentamicin and Levofloxacin. Although in terms of their potency we did not notice any statistical significance (Table III) against wide range of bacterial infections in the samples, however, it seemed clear that this 1st generation beta-lactam antibiotic developed in 1967 still having antibacterial activity against diverse bacteria belongs to both gram-positive and gramnegative classes.

TABLE III: ANTIBIOTICS HIGHLY SENSITIVE AGAINST BACTERIAL SAMPLES OBTAINED FROM VARIOUS COMMERCIAL FARMS

\begin{tabular}{ccccc}
\hline $\begin{array}{c}\text { Name of } \\
\text { antibiotics }\end{array}$ & $\begin{array}{c}\text { Total } \\
\text { samples }\end{array}$ & $\begin{array}{c}\text { No of samples } \\
\text { showed highest } \\
\text { sensitivity }\end{array}$ & $\begin{array}{c}\text { Percentage } \\
(\%)\end{array}$ & $\begin{array}{c}\mathrm{P} \\
\text { value }\end{array}$ \\
\hline Neomycin & 30 & 7 & 23.33 & 0.81 \\
Gentamicin & 30 & 6 & 20 & 8411 \\
Levofloxacin & 30 & 7 & 23.33 & $\mathrm{NS}$ \\
Cephalexin & 30 & 10 & 33.33 & \\
\hline
\end{tabular}

$\mathrm{NS}=$ Non Significant at 5\% level of probability.

$* *$ Significant at $5 \%(\mathrm{p}<0.05)$.

Next to Cephalexin, Levofloxacin, one of the effective 3rd generation quinolones normally applied through water medications in poultry was found highly sensitive too. Similar sensitivity also observed by Neomycin, a broad spectrum aminoglycosides developed in 1949 still highly effective against human, large animals and poultry. Gentamicin, another aminoglycoside developed in 1963 showed lowest sensitivity but still highly potent to be commercially used against poultry. Antibiotic sensitivity by Cephalexin, Levofloxacin, Neomycin and Gentamicin was $33.33 \%, 23.33 \%, 23.33 \%$ and $20 \%$ respectively as highlighted in detail in Fig. 1.

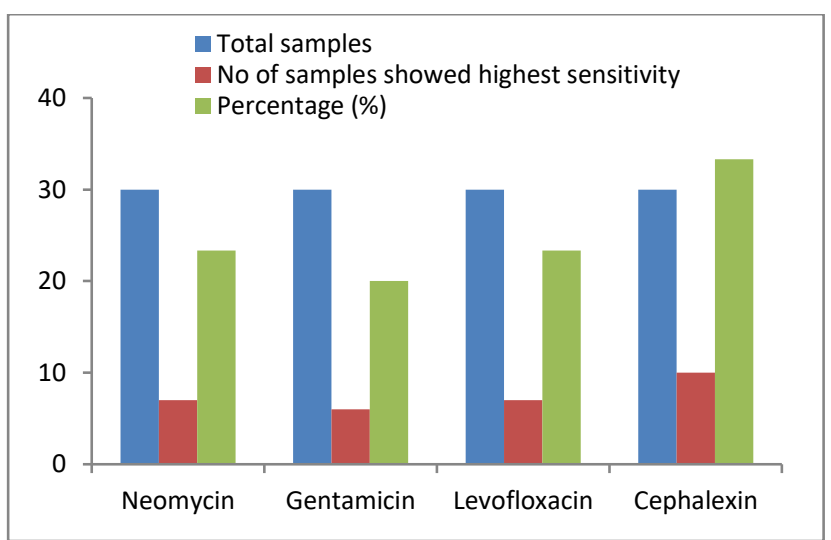

Fig. 1. The graph illustrates the types of antibiotics highly sensitive against bacterial samples. 


\section{B. Antibiotics quite Sensitive against Bacterial Samples}

Doxycycline, a semi-synthetic tetracycline antibiotic although widely used as an effective anti-mycoplasmal and anti-chlamydial drugs did not show a promising result. Only 1 out of 30 samples it showed quite sensitivity which is only $3.33 \%$ in total (Table IV). The drug is not recommended for laying hens. Sulfonamides, also known as sulfa or sulpha drugs are synthetic antibiotics with a wide spectrum against most gram-positive and many gram-negative organisms. This drug too was an unpromising candidate for our experiment. Its affectivity was $6.67 \%$ that is 2 out of 30 samples showed a quite sensitivity.

TABLE IV: ANTIBIOTICS QUITE SENSITIVE AGAINST BACTERIAL SAMPLES OBTAINED FROM VARIOUS COMMERCIAL FARMS

\begin{tabular}{ccccc}
\hline $\begin{array}{c}\text { Name of } \\
\text { antibiotics }\end{array}$ & $\begin{array}{c}\text { Total } \\
\text { samples }\end{array}$ & $\begin{array}{c}\text { No of samples } \\
\text { showed quite } \\
\text { sensitivity }\end{array}$ & $\begin{array}{c}\text { Percentage } \\
(\%)\end{array}$ & P value \\
\hline Neomycin & 30 & 23 & 76.67 & \\
Gentamicin & 30 & 24 & 80 & \\
Levofloxacin & 30 & 21 & 70 & $0.0000974^{* *}$ \\
Cephalexin & 30 & 20 & 66.67 & \\
Sulfonamide & 30 & 2 & 6.67 & \\
Doxycycline & 30 & 1 & 3.33 & \\
\hline
\end{tabular}

Striking difference with a statistical significance $(\mathrm{P}<0.05)$ was observed between Sulfonamide (6.67\%) and/or Doxycycline $(3.33 \%)$ versus other four experimental antibiotics like Neomycin (76.67\%), Gentamicin (80\%), Levofloxacin $(70 \%)$ and Cephalexin $(66.67 \%)$ as described in Fig. 2.

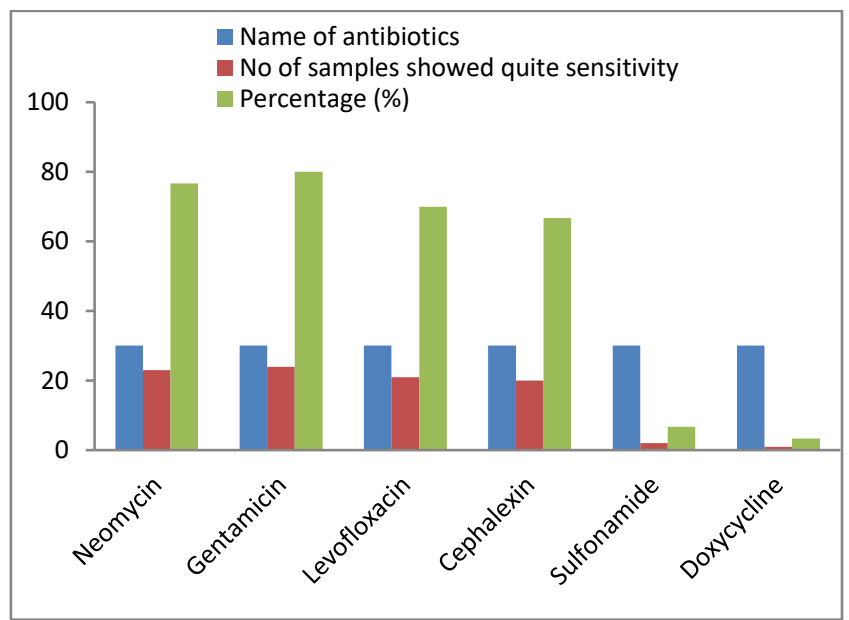

Fig. 2. The graph illustrates the types of antibiotics quite sensitive against bacterial samples.

\section{Antibiotics Moderately Sensitive against Bacterial Samples}

Ciprofloxacin a WHO recommended Fluoroquinolone has shown non-promising sensitivity. In our experiment only 2 out of 30 samples that is $6.67 \%$ cases showed moderate sensitivity. Affectivity of other Fluoroquinolone, Levofloxacin showed an asymmetric potency ranging from high $(23.33 \%$, Table III) to quite (70\%, Table IV) to moderate (6.67\%, Table V). Doxycycline was proven to be the most moderately sensitive antibiotic followed by sulfonamide. In our experiment 18 out of 30 that are $60 \%$ samples were moderately sensitive against antibiotic disc containing Doxycycline.
TABLE V: ANTIBIOTICS MODERATELY SENSITIVE AGAINST BACTERIAL SAMPLES OBTAINED FROM VARIOUS COMMERCIAL FARMS

\begin{tabular}{ccccc}
\hline $\begin{array}{c}\text { Name of } \\
\text { antibiotics }\end{array}$ & $\begin{array}{c}\text { Total } \\
\text { samples }\end{array}$ & $\begin{array}{c}\text { No of samples } \\
\text { showed } \\
\text { moderately } \\
\text { sensitive }\end{array}$ & $\begin{array}{c}\text { Percentage } \\
(\%)\end{array}$ & P value \\
\hline Ciprofloxacin & 30 & 2 & 6.67 & \\
Levofloxacin & 30 & 2 & 6.67 & $0.000398^{* *}$ \\
Sulfonamide & 30 & 15 & 50 & \\
Doxycycline & 30 & 18 & 60 & \\
\hline
\end{tabular}

We observed nearly similar result in case of Sulfonamide treatment, where 15 out of 30 i.e., $50 \%$ cases we noticed moderate sensitivity.

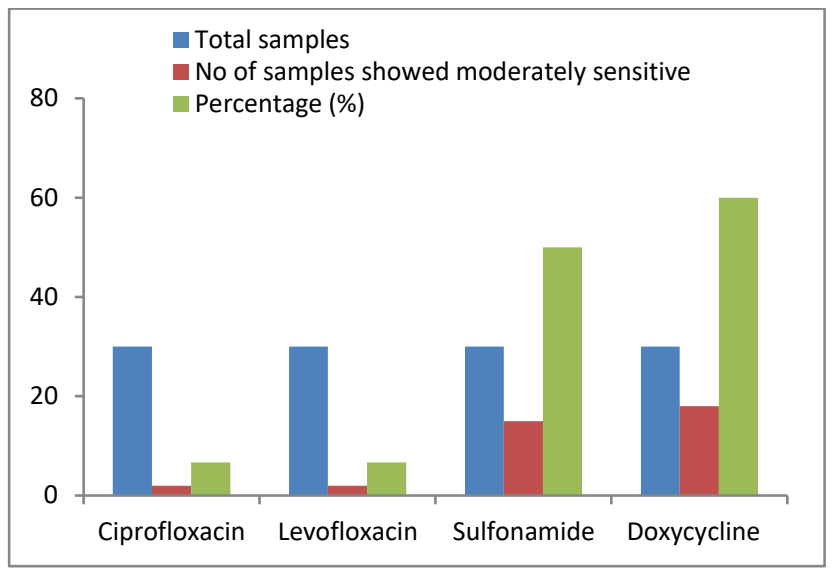

Fig. 3. The graph illustrates the types of antibiotics moderately sensitive against bacterial samples.

\section{Antibiotics Weakly Sensitive against Bacterial Samples}

Owing to a moderately higher oral bioavailability, Amoxicillinis administered at a dosage of $10 \mathrm{mg} / \mathrm{kg}$ at $24 \mathrm{~h}$ intervals and effective in treating a variety of systemic infections in poultry. However, in our experiment this drug was mostly $(80 \%)$ found weekly sensitive against mixed bacterial colony derived from commercial poultry liver samples (Fig. 4).

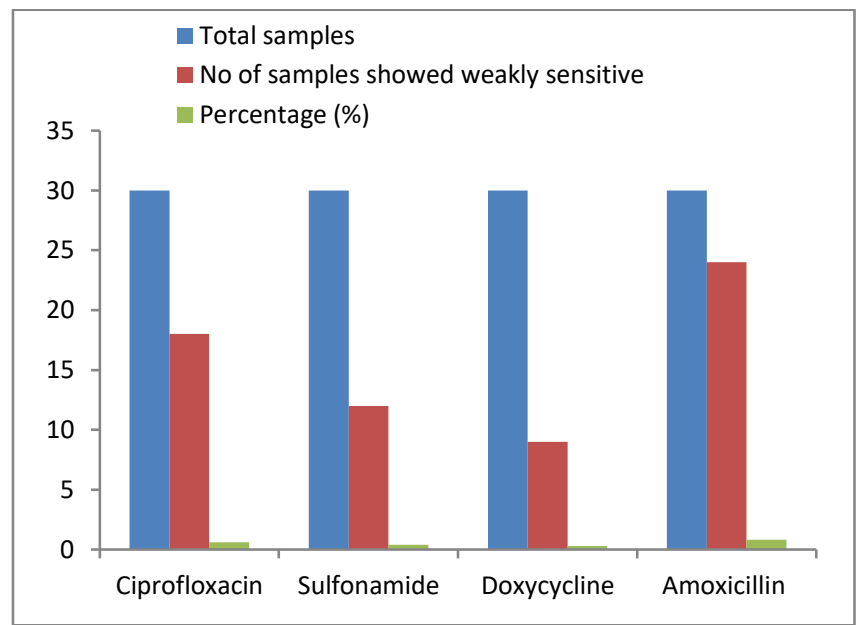

Fig. 4. The graph illustrates the types of antibiotics weakly sensitive against bacterial samples.

Doxycycline on the other hand showed moderate $(60 \%$, Table V) to weak sensitivity (30\%, Table VI). Ciprofloxacin was mostly found weekly sensitive (60\%), whereas Sulfonamide always stands in the mid-point ranging from moderate $(50 \%)$ to weekly $(40 \%)$ sensitive. We did not, 
however, notice any statistical association $(\mathrm{P}>0.05)$ amongst these antibiotics (Table V).

TABLE VI: ANTIBIOTICS WEAKLY SENSITIVE AGAINST BACTERIAL SAMPLES OBTAINED FROM VARIOUS COMMERCIAL FARMS

\begin{tabular}{ccccc}
\hline $\begin{array}{c}\text { Name of } \\
\text { antibiotics }\end{array}$ & $\begin{array}{c}\text { Total } \\
\text { samples }\end{array}$ & $\begin{array}{c}\text { No of samples } \\
\text { showed weakly } \\
\text { sensitive }\end{array}$ & $\begin{array}{c}\text { Percentage } \\
(\%)\end{array}$ & P value \\
\hline Ciprofloxacin & 30 & 18 & $60 \%$ & \\
Sulfonamide & 30 & 12 & $40 \%$ & 0.140764 \\
Doxycycline & 30 & 9 & $30 \%$ & NS \\
Amoxicillin & 30 & 24 & $80 \%$ & \\
\hline
\end{tabular}

\section{E. Antibiotics not Sensitive against Bacterial Samples}

In our experiment, we noticed a large variation of antibiotic potency against bacterial samples on the agar media. In some cases, Ciprofloxacin, Sulfonamide, Doxycycline and Amoxicillin showed no sensitivity to the bacterial samples at all. Within these antibiotics we could ascertain significant statistical association $(\mathrm{P}<0.05)$ (Table VII). Aforementioned antibiotics were not sensitive to the bacterial samples at the rate of Ciprofloxacin (33.33\%), Sulfonamide (3.33\%), Doxycycline (6.67\%) and Amoxicillin (20\%) (Fig. 5).

TABLE VII: ANTIBIOTICS Not SENSITIVE AGAINST BACTERIAL SAMPLES OBTAINED FROM VARIOUS COMMERCIAL FARMS

\begin{tabular}{ccccc}
\multicolumn{5}{c}{ OBTAINED FROM VARIOUS COMMERCIAL FARMS } \\
$\begin{array}{c}\text { Name of } \\
\text { antibiotics }\end{array}$ & $\begin{array}{c}\text { Total } \\
\text { samples }\end{array}$ & $\begin{array}{c}\text { No of samples } \\
\text { showed not } \\
\text { sensitive }\end{array}$ & $\begin{array}{c}\text { Percentage } \\
(\%)\end{array}$ & P value \\
\hline Ciprofloxacin & 30 & 10 & $33.33 \%$ & \\
Sulfonamide & 30 & 1 & $3.33 \%$ & $0.029508^{* *}$ \\
Doxycycline & 30 & 2 & $6.67 \%$ & \\
Amoxicillin & 30 & 6 & $20.0 \%$ & \\
\hline
\end{tabular}

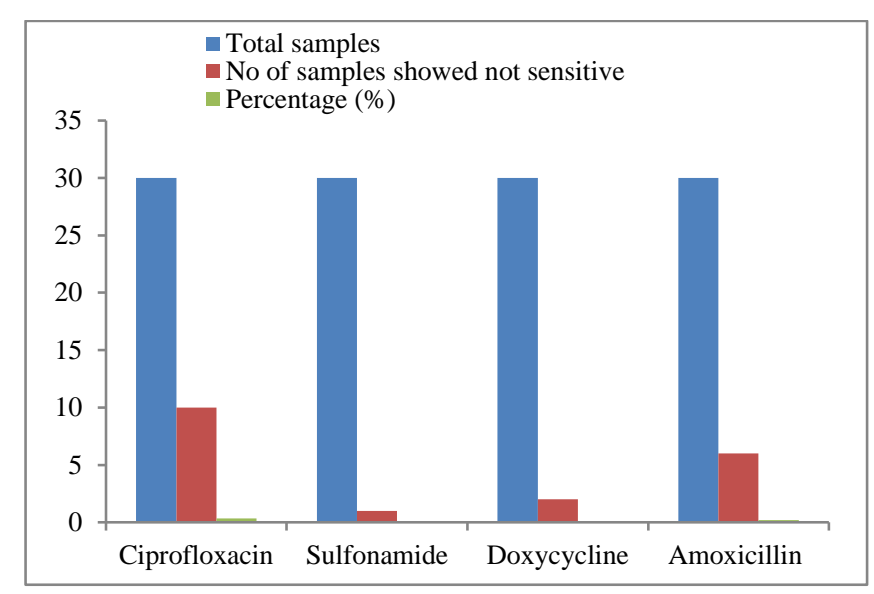

Fig. 5. The graph illustrates the types of antibiotics not sensitive against bacterial samples.

\section{DISCUSSION}

Poultry industry in Bangladesh has made remarkable progress during the last few decades from backyard poultry rearing to a considerably organized commercial industry. This industry is playing a major role in poverty alleviation and income generation. Despite rapid growth of this industry, in the recent years, poultry farming has been hampered by the outbreak of fatal infectious diseases. One of the key reasons for considerably higher occurrence of infectious diseases is antimicrobial resistance. AMR is in fact a global health concern [14]. Over recent years a considerable body of evidence highlighting that the contributing factors for the development of AMR have been due to the intensification of farming practices in much of the developing world and the excessive use of antimicrobials in that production systems [15], [16]. Although Escherichia coli, Enterococcus spp., Staphylococcus aureus as well as foodborne zoonotic pathogens, such as non-typhoidal Salmonella and Campylobacter spp are implicated for the occurrence of AMR in animal production systems, however, with some exceptions, relatively little is known on the development of antibiotic resistance in poultry [17]-[22]. There is also scarcity of knowledge on AMR in important zoonotic pathogens such as $C$. psittaci and M. avium detected from sick poultry.

Poultry is being reared round the globe, and chicken is the most extensively farmed species, with over 90 billion tons of chicken meat produced per year [23]. The production costs are low and there is no cultural and religious borderline in poultry consumption. A large variety of antibiotics and other antimicrobials are used to raise poultry in most of the countries, including Bangladesh, mostly administered orally, in order to prevent and treat various diseases, as well as promoting growth and productivity [24]-[26]. Such antimicrobials to a great extent are considered to be of critical and highly important for human medicine [25]. The indiscriminate use of antibiotics in poultry farming is likely to hasten the development of resistance in pathogens, as well as in commensal organisms. Concerning the fact for the development of antimicrobial resistance in bacteria from poultry production, there is human health concerns also because of the presence of antibiotic residues in eggs and meats [27], [28]. Taking the gaps in the knowledge of antibiotic resistance in the commercial poultry farms in Bangladesh, in our experiment we endeavored elucidating the potency of regularly used antibiotics such as Neomycin, Gentamicin, Levofloxacin, Ciprofloxacin, Doxycycline, Sulfonamide, Amoxicillin and Cephalexin against bacterial samples obtained from commercial poultry farms. A total of 30 liver (birds) samples of which 24 from layer birds and 6 from broiler birds were collected from 10 commercial poultry farms at Rajshahi region and were subjected to Kirby-Bauer disc diffusion test to detect sensitivity of commonly used antibiotics against bacterial infection concerning the ultimate scenario of mostly talked context called antimicrobial resistance in case of poultry production.

In our experimental findings among the highly sensitive antibiotics, Cephalexin has been proven to be more effective and its percentage is $33.33 \%$ than its other counterparts like Neomycin $(23.33 \%)$, Gentamicin $(20 \%)$ and Levofloxacin $(23.33 \%)$. Scientists from India Sarangi and Panda also found higher sensitivity of Cephalexin (71.4\%), Levofloxacin $(85.7 \%)$ and Gentamycin $(85.7 \%)$ against avian Isolates of Pasteurella multocida [29]. Similar findings were also reported in India [30]. In line with that Boamah also observed similar sensitivity of Cephalexin and Gentamicin against livestock and poultry associated with Staphylococci infection [31]. Hasan et al., noted that the salmonella isolates show $100 \%$ sensitivity and E. coli isolates show $76.92 \%$ sensitivity to neomycin [32].

Although in terms of their potency we did not notice any statistical significance against wide range of bacterial infections in the samples, however, it seemed clear that this 1st generation beta-lactam antibiotic developed in 1967 still 
having antibacterial activity against diverse bacteria belongs to both gram-positive and gram-negative classes. Next to Cephalexin, Levofloxacin, one of the effective 3rd generation quinolones normally applied through water medications in poultry was found highly sensitive too. Similar sensitivity also observed by Neomycin, a broad spectrum aminoglycosides developed in 1949 still highly effective against human, large animals and poultry. Gentamicin, another aminoglycoside developed in 1963 showed lowest sensitivity but still highly potent to be commercially used against poultry.

Doxycycline, a semi-synthetic Tetracycline antibiotic although widely used as an effective anti-mycoplasmal and anti-chlamydial drugs did not show a promising result in our study. Only 1 out of 30 samples it showed quite sensitivity which is only $3.33 \%$ in total. Hasan et al., reported that $50 \%$ of salmonella isolates and $53.57 \%$ of $E$. coli isolates show resistance properties to Doxycycline antibiotics [32]. In our study Doxycycline show moderate to weak sensitivity as $60 \%$ to $40 \%$ and it is an alarming report for us because it will be very hard to confer an actual protection against bacterial infection concerning this type of sensitivity with Doxycycline.

In a study showed Sulfamethoxazole, a Sulfonamide drug renders $67 \%$ resistance against Avian Colibacillosis [33]. In our experiment we did not notice any strong sensitivity of Sulfonamide against bacterial isolates. This drug has only showed a quite $6.67 \%$, moderate $50 \%$ or weak $40 \%$ sensitivity. In $3.33 \%$ cases we notice complete lack of sulfa drug sensitivity against mixed bacterial samples provided a clue of developing anti-sulfa resistance in commercial farms of Bangladesh.

Similar to sulfa drugs we didn't find a higher sensitivity of Ciprofloxacin and to some extent this sensitivity falls within the range of moderate $(6.67 \%)$ to weaker $(60 \%)$ level. In our studies, among 8 antibiotics in question, Ciprofloxacin showed highest resistance $(33.33 \%)$. This is worrisome as the drug is still being widely considered antimicrobial for commercial poultry industry. Contrary to our findings, higher sensitivity $(79.7 \%)$ and less bacterial resistance $(20.3 \%)$ against Ciprofloxacin were also noted [34]. They also showed a pattern of antibiotic resistance in case of E. coli isolates from slaughtered chickens considering 10 antibiotics where Amoxiclav and Cotrimoxazole were $100 \%$ resistant and the others were as follows Chloramphenicol 75.9\%, Amoxicillin $73.4 \%$, Streptomycin 72.2\%, Sparfloxacin 67.1\%, Gentamycin 44.3\%, Pefloxacin $31.6 \%$ and Ofloxacin $26.6 \%$. A greater dissimilarity between our research and that of other studies described above could be due to various reasons such as geographical location and the use of different antibioticregimen, seasonal variation, patterns of disease occurrence, different management systems etc. Here it has been clearly seen that the organism was less resistant to Ciprofloxacin comparing other antibiotics whereas in our study we found that Ciprofloxacin is highly resistant to our examined bacterial samples of commercial poultry farms.

Data from our experiment indicate a high prevalence of doxycycline resistance which is indiscriminately being used in poultry production. Our finding is in agreement with Sandoz and Rockey who observed that tetracycline was largely getting resistant against avian chlamydiosis [35]. In our experiment we could ascertain significant statistical association $(\mathrm{P}<0.05)$ among Ciprofloxacin, Sulfonamide, Doxycycline and Amoxicillin. Aforementioned antibiotics were not sensitive to the bacterial samples at the rate of Ciprofloxacin $(33.33 \%)$, Sulfonamide (3.33\%), Doxycycline $(6.67 \%)$ and Amoxicillin (20\%). Agyare et al., observed Ciprofloxacin resistance (42\%) against avian colibacillosis [33]. Hasan et al., reported about the antibiotic resistance against avian colibacillosis with Amoxicillin and Ciprofloxacin were $84.62 \%$ and $100 \%$ respectively [32]. In our experiment, 10 out of 30 samples were not sensitive to Ciprofloxacin, i.e., $33.33 \%$ cases the drug seemed resistant against mixed bacterial isolates. In $20 \%$ cases, we noticed that Amoxicillin was insensitive to bacterial isolates. Nhung et al., in their review article cited different researches round the world with emergence of similar Amoxicillin resistance against bacterial diseases of poultry [36].

From the results of our study, it is found that some antibiotics like Ciprofloxacin, Amoxicillin, Doxycycline and Sulfonamides to some extents are gradually losing their effectivity against microbial infection, where some antibiotics such as Cephalexin, Neomycin, Gentamicin and Levofloxacin were found possessing superior antimicrobial.

potency. These antibiotics in some cases showed comparatively slower activity as it is reflected in our experiment where $6.67 \%$ cases Levofloxacin was found moderately sensitive. Indiscriminate use of this low sensitive drugs is exacerbating the evil problems of antibiotic resistance as described by Hasan et al., who reported that Ciprofloxacin is resistant against avian colibacillosis as $100 \%$ [32]. And in our present study we found Ciprofloxacin is resistant as $33.33 \%$ against bacterial samples but reality is that even if in some farms antibacterial resistance developed Ciprofloxacin is still being used to their therapeutic regimen because they have no documented profile of antibiotic use and no idea about antibiotic sensitivity test. Similar pattern of random use is also true for other types of antibiotics. This type of malpractice in case of antibiotic use causes an ultimate threat to our poultry industry and consequently to human health.

As discovered antibiotics becoming resistant day by day and there is persistent inability to develop newer antibiotics, we should consider about antibiotic sensitivity test solely so that, we can save our era from the curse of antimicrobial resistance. From this point of view, we conduct our research work to identify antibiotics through antibiotic sensitivity test which are more effective, and which are already become resistant so that we can provide a message to our poultry practitioner about the actual scenario of antibiotic profile that will help to ensure a strong protection against microbial infection and to establish a profitable farming system that will add a gorgeous value to our national economy.

\section{CONCLUSION}

Poultry is the most extensively farmed species around the world. A large variety of antibiotics and other antimicrobials are mostly administered orally, in order to prevent and treat various diseases, as well as promoting growth and productivity of poultry. In order to fill the gaps of the 
knowledge of existing AMR status of poultry we conducted a thorough research.

In this study, we found antibiotics like ciprofloxacin, amoxicillin, doxycycline, and Sulfonamides to some extents are gradually losing their effectivity against microbial infection. On the other hand, some other antibiotics such as Cephalexin, Neomycin, Gentamicin and Levofloxacin still retain superior antimicrobial potency. In some cases, antibiotics showed comparatively slower activity as it is reflected in our experiment where $6.67 \%$ cases levofloxacin was found moderately sensitive. Indiscriminate uses of these low sensitive antimicrobials are exacerbating the existing resistance to a greater dimension.

In most countries, poultry farming is conducted without adequate veterinary supervision, and a wide range of antimicrobials is normally available to farmers "over the counter." Prudent use practices should be adopted such as restricting the access for use of antimicrobials that are considered to be important for human medicine in poultry production. Like industrialized countries such restrictions should also be enforced in poultry industry of Bangladesh. Other measures such as education on good farming practices and building up a knowledge base on the AMR profile of poultry pathogens will encourage responsible antimicrobial usage, that contribute to diminish treatment failure against poultry diseases, hence, helping reduce accompanying economic losses. To wrap up, in our experiment we tried to elucidate the status of antimicrobial resistance of commercially available antibiotics being Used in poultry production system and we described our results in detail, however, further research is needed to shed more light on that.

\section{ACKNOWLEDGMENTS}

The authors gratefully thank the Nourish Poultry \& Hatchery Limited Bangladesh for rendering the technical support in carrying out all the research experiments in its facilities.

\section{CONFLICTS OF INTEREST}

The authors declare no conflict of interest.

\section{REFERENCES}

[1] M. A. Hamid, M. A. Rahman, S. Ahmed, and K. M. Hossain, "Status of Poultry Industry in Bangladesh and the Role of Private Sector for its Development", Asian Journal of Poultry Science; vol. 11, pp. 1-13, 2017.

[2] M. I. Khan, J. Ferdous, M. R. A. Ferdous, M. S. Islam, K. Rafiq, U. K. Rima, "Study on indiscriminate use of antibiotics in poultry feed and residues in broilers of Mymensingh city in Bangladesh", Progressive Agriculture, vol. 29, pp. 345-352, 2018.

[3] K. W. Lee, Y. H. Hong, S. H. Lee, S. I. Jang, M. S. Park, D. A. Bautista, G. D. Ritter, W. Jeong, H. Y. Jeoung, D. G. An, A. P. Lillehoj, H. S. Lillehoj, "Effects of anti-coccidial and antibiotic growth promoter programs on broiler performance and immune status", Res Vet Sci, vol. 93, pp. 721-728, 2012.

[4] J. Davies and D. Davies, "Origins and evolution of antibiotic resistance", Microbiol Mol Biol Rev, vol. 74, pp. 417-433, 2010.

[5] J. G. Bartlett, D. N. Gilbert, B. Spellberg, (2013). "Seven ways to preserve the miracle of antibiotics", Clin Infect Dis; vol. 56, pp. 1445$1450,2013$.
[6] B. Spellberg and D. N. Gilbert, "The future of antibiotics and resistance: a tribute to a career of leadership by John Bartlett", Clin Infect Dis, VOL. 59, pp. 71-75, 2014.

[7] C. L. Ventola, "The antibiotic resistance crisis: part 1: causes and threats", Pharmacy and Therapeutics, VOL. 40, pp. 277-283, April, 2015.

[8] A. F. Read and R. J. Woods, “Antibiotic resistance management”, Evol Med Public Health, VOL. 147, 2014.

[9] B. D. Lushniak, "Antibiotic resistance: a public health crisis", Public Health Rep; VOL. 129, pp. 314-316, 2014.

[10] S. H. Jeong, G. Widyanugraha, "Common problems in poultry liver health and mycotoxin risk", BIOMIN slovensko s. r. o, https://www2.biomin.net/ua/stati/common-problems-in-poultry-livehealth-and-mycotoxin-risk/, July, 2019.

[11] P. Popelka, J. Nagy, R. Germuska, S. Marcincak, P. Jevinova, D. A. Rijk, "Comparison of various assays used for detection of beta-lactam antibiotics in poultry meat", Food Additive \& Contaminant", vol. pp. 557-562, 2005.

[12] S. Aryal, "Mueller Hinton Agar (MHA) - Composition, Principle, Uses and Preparation", Microbiology Info.com. https://microbiol ogyinfo.com/mueller-hinton-agar-mha-composition-principle-usesand-preparation/, 2018.

[13] R. S. Buriro, F. Habib, R. Rind, M.A. Shah, R. R. Kaleri, A. K. Samoon, M. A. Talpur and N. Goswami N, "Antibiotic sensitivity tests of various micro-organisms from poultry eggs", Pure and Applied Biology; vol. 6, pp. 1417-1426, 2017.

[14] WHO (World Health Organization), "Antimicrobial Resistance: Global Report on Surveillance", Available from http://www.who.int/drug resistance/documents/surveillancereport/en/, 2014.

[15] B. M. Marshall and S. B. Levy, "Food animals and antimicrobials: impacts on human health", Clin Microbiol Rev, vol. 24:718-33. -15.

[16] T. P. Van Boeckel, C. Brower, M. Gilbert, "Global trends in antimicrobial use in food animals" Proc Natl Acad Sci, vol. 112, pp. 5649-5654, 2015.

[17] D. A. Tadesse, S. Zhao, E. Tong, S. Ayers, A. Singh, M. J. Bartholomew, "Antimicrobial drug resistance in Escherichia coli from humans and food animals, United States, 1950-2002", Emerg Infect Dis; vol. 18, pp. 741-9, 2012.

[18] G. A. Luna-Galaz, V. Morales-Erasto, C. G. Peñuelas-Rivas, P. J. Blackall and E. Soriano-Vargas, "Antimicrobial Sensitivity of Avibacteriumparagallinarum Isolates from Four Latin American Countries", Avian Diseases, vol. 60, pp. 673-676, 2016.

[19] C. Simoneit, E. Burow, B. A. Tenhagen, A. Käsbohrer, "Oral administration of anti-microbials increase antimicrobial resistance in $E$. coli from chicken-a systematic review", Prev Vet Med, vol. 118, pp. 17, 2015.

[20] V. Bortolaia, C. Espinosa-Gongora, L. Guardabassi, (2016). "Human health risks associated with antimicrobial-resistant enterococci and Staphylococcus aureus on poultry meat", Clin Microbiol Infect, vol. pp. 130-40, 2016.

[21] T. T. Van, H. N. Nguyen, P. M. Smooker, P. J. Coloe, "The antibiotic resistance characteristics of non-typhoidal Salmonella enterica isolated from food-producing animals, retail meat and humans in South East Asia", Int J Food Microbiol, vol. 154, pp. 98-106, 2012.

[22] B. Custer, J. A. Steele, B. A. Wilcox, J. Xu, "Intensified food production and correlated risks to human health in the Greater Mekong Sub region: a systematic review", Environ Health; vol. 14, pp. 43, 2015.

[23] FAO (Food and Agriculture Organization of the United Nations), FAOSTAT: Live Animals Data, Available from http://www.fao.org/, 2017.

[24] A. Agunos, D. Leger, and C. Carson, "Review of antimicrobial therapy of selected bacterial diseases in broiler chickens in Canada," Can Vet $J$, vol.53, pp. 1289-300, December 2012.

[25] M. F. Landoni and G. Albarellos, "The use of antimicrobial agents in broiler chickens", Vet J, vol. 205, pp. 21-27, 2015.

[26] S. W. Page and P. Gautier, "Use of antimicrobial agents in livestock", Rev Sci Tech, vol. 31, pp. 145-88, 2012.

[27] M. Reig and F. Toldra, "Veterinary drug residues in meat: concerns and rapid methods for detection", Meat Sci, vol. 78, pp. 60-67, 2008.

[28] V. Goetting, K. A. Lee, L. A. Tell, "Pharmacokinetics of veterinary drugs in laying hens and residues in eggs: a review of the literature" $J$ Vet Pharmacol, vol. 34, pp. 521-56, 2011.

[29] L. N. Sarangi and H. K. Panda, "Antibiotic Sensitivity of Avian Isolates of Pasteurella multocida", Indian Vet. J, vol. 88, pp.85 - 86, 2011.

[30] S. B. Shivachandra, A. A. Kumar, A. Biswas, M. A. Ramakrishnan, P. Singh Vijendra, S. K. Srivastawa, "Antibiotic sensitivity patterns among Indians strains of avian Pasteurella multocida", Trop Anim Health Prod, vol. 36, pp. 743-750, 2004. 
[31] Boamah VE, Agyare C, Odoi H, Adu F, Gbedema S, Dalsgaard A (2017) Prevalence and antibiotic resistance of coagulase-negative Staphylococci isolated from poultry farms in three regions of Ghana. Infection and Drug Resistance; 10:175-183.

[32] M. M. Hassan, K. B. Amin, M. Ahaduzzaman, M. Alam, M. S. A. Faruk, I. Uddin, "Antimicrobial Resistance Pattern against E. coli and Salmonella in Layer Poultry". Research Journal for Veterinary Practitioners; vol. 2, pp. 30-35, 2014.

[33] C. Agyare, V. E. Boamah, C. N. Zumbi and F. B. Osei, "Antibiotic use in poultry production and its effects on bacterial resistance", in Antimicrobial Resistance-A Global Threat, Open access peer-reviewed Edited Volume, Intech Open, Ed. London: SW7 2QJ, 2018, pp. 33-51.

[34] I. F. Odoemene and O. O. Enwere, "Susceptibility pattern to common antibiotics of intestinal Escherichia coli from slaughtered commercially grown chickens", International Journal of Contemporary Medical Research, vol. 5, pp. 25-30, 2018.

[35] K. M. Sandoz and D. D. Rockey, "Antibiotic resistance in Chlamydiae", Future Microbiol; vol. 5, pp. 1427-1442, 2010.

[36] N. T. Nhung, N. Chansiripornchai and J. J. Carrique-Mas, "Antimicrobial Resistance in Bacterial Poultry Pathogens", A Review, frontiers in Veterinary Science, vol. 4, https://doi.org/10.3389/fvets.2017.00126, August, 2017.

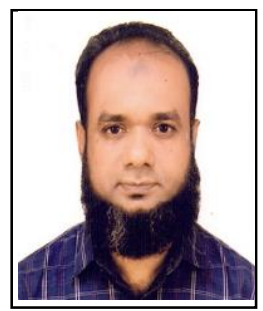

Aurangazeb Kabir is an Associate Professor in the Department of Veterinary and Animal Sciences, University of Rajshahi, Bangladesh. He graduated on Doctor of Veterinary Medicine (DVM), and got his Master's degree (MS in Medicine) from Bangladesh Agricultural University. He achieved his $\mathrm{PhD}$ in Medical Science from Gifu University in Japan.

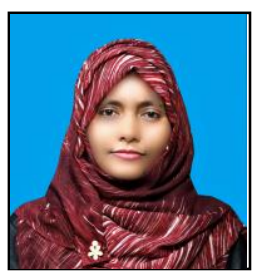

Most. Sabina Yasmin is a graduate of Doctor of Veterinary Medicine, and earned her Master's degree (Master of Science in Medicine) from the Department of Veterinary and Animal Sciences of Rajshahi University, Bangladesh.

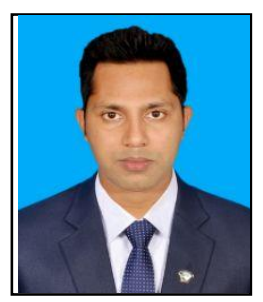

Md. Golam Sarwar is a graduate of Doctor of Veterinary Medicine and completed Master's (Master of Science in Medicine) from the Department of Veterinary and Animal Sciences of Rajshahi University, Bangladesh.

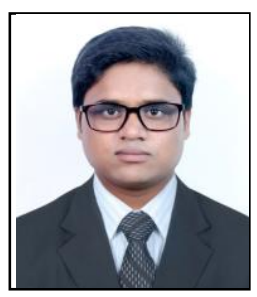

Md. Obaidullah Al Masum is a graduate of Doctor of Veterinary Medicine, and got Master's degree (Master of Science in Medicine) from the Department of Veterinary and Animal Sciences of Rajshahi University, Bangladesh.

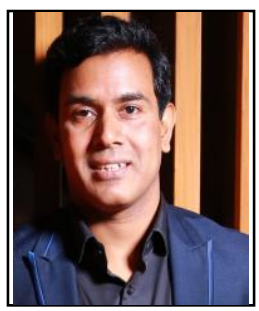

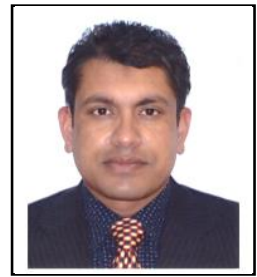

Mohammad Mahbubur Rahman is a Professor in the Department of Veterinary and Animal Sciences, University of Rajshahi, Bangladesh. He graduated on Doctor of Veterinary Medicine (DVM) and "earned his Master's degree (MS in Medicine) from Bangladesh Agricultural University. He obtained his $\mathrm{PhD}$ from Milan University, Italy. 